Document downloaded from:

http://hdl.handle.net/10251/81748

This paper must be cited as:

Lucas-Granados, B.; Sánchez Tovar, R.; Fernández Domene, RM.; Garcia-Anton, J. (2016). Study of the annealing conditions and photoelectrochemical characterization of a new iron oxide bi-layered nanostructure for water splitting. Solar Energy Materials and Solar Cells. 153:68-77. doi:10.1016/j.solmat.2016.04.005.

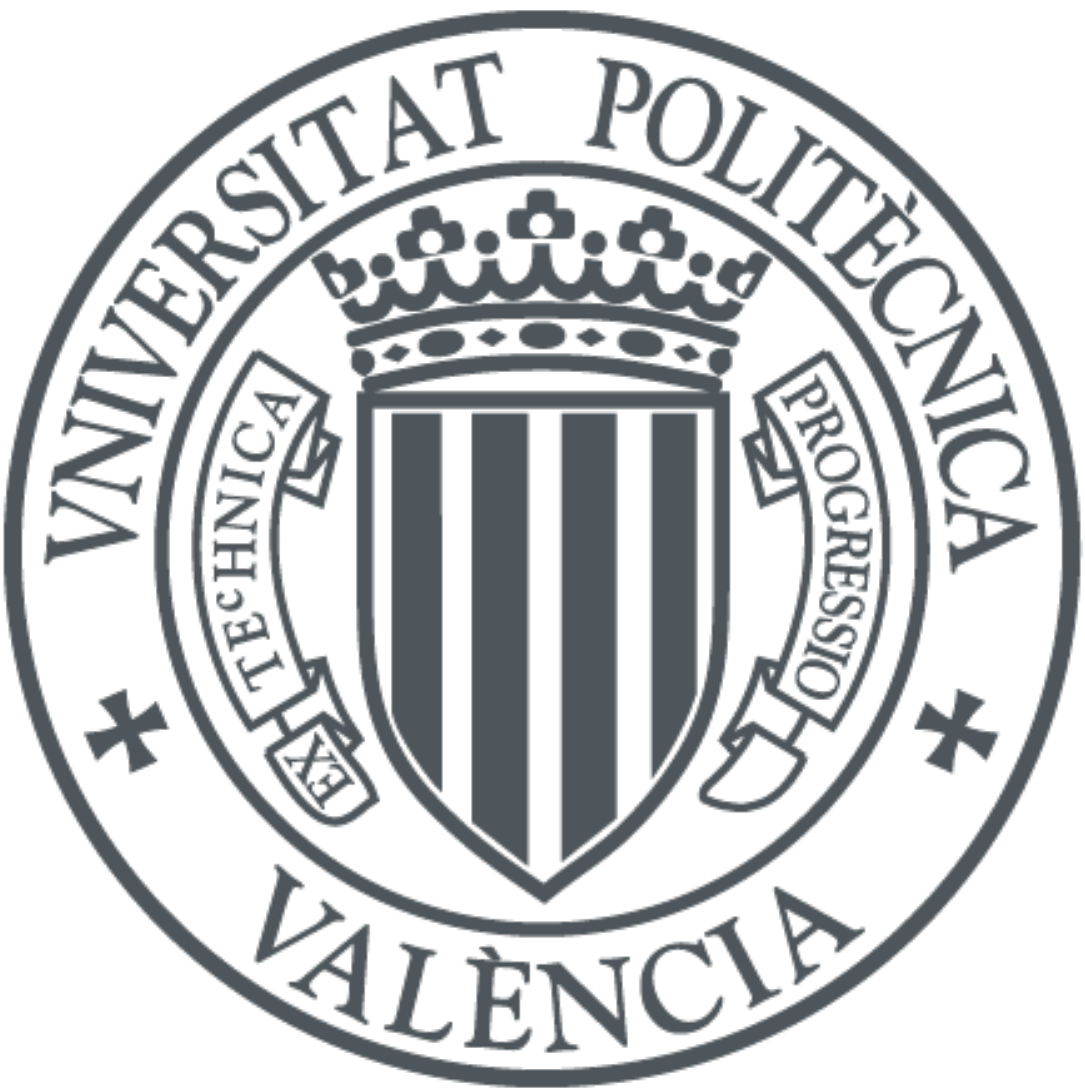

The final publication is available at

http://doi.org/10.1016/j.solmat.2016.04.005

Copyright Elsevier

Additional Information 


\title{
Study of the annealing conditions and photoelectrochemical characterization of a new iron oxide bi-layered nanostructure for water splitting
}

\author{
Bianca Lucas-Granados, Rita Sánchez-Tovar, Ramón M. Fernández-
} Domene, Jose García-Antón*

Ingeniería Electroquímica y Corrosión (IEC). Instituto Universitario de Seguridad Industrial, Radiofisica y Medioambiental (ISIRYM). Universitat Politècnica de València. Camino de Vera s/n, 46022 Valencia, Spain.

*jgarciaa@iqn.upv.es

\begin{abstract}
Iron oxide nanostructures have emerged as promising materials for being used as photocatalysts for hydrogen production due to their advantageous properties. However, their low carrier mobility and short hole diffusion length limit their efficiency in water splitting. To overcome these drawbacks, in the present study, we synthetized a new hematite $\left(\alpha-\mathrm{Fe}_{2} \mathrm{O}_{3}\right)$ bi-layered nanostructure consisting of a top nanosphere layer and a nanotubular underneath one by electrochemical anodization. Annealing parameters such as temperature, heating rate and atmosphere were studied in detail in order to determine the optimum annealing conditions for the synthetized nanostructure. The obtained new bi-layered nanostructure was characterized by Field Emission Scanning Electron Microscopy, Raman spectroscopy, Mott-Schottky analysis and Electrochemical Impedance Spectroscopy. The results show the best water splitting performance for the bi-layered nanostructure annealed in argon atmosphere at $500{ }^{\circ} \mathrm{C}$ at a heating rate of 15
\end{abstract}


${ }^{\circ} \mathrm{C} \cdot \mathrm{min}^{-1}$ achieving a photocurrent density of $\sim 0.143 \mathrm{~mA} \cdot \mathrm{cm}^{-2}$ at $1.54 \mathrm{~V}$ (vs. RHE).

The results indicate that the bi-layered nanostructure is an efficient photocatalyst for applications such as water splitting.

Keywords: hematite, photocatalyst, anodization, water splitting, annealing.

\section{Introduction}

Iron can be oxidized to different states such as $\mathrm{FeO}, \mathrm{Fe}_{2} \mathrm{O}_{3}$ and $\mathrm{Fe}_{3} \mathrm{O}_{4}$ [1-3]. Among these oxides, hematite $\left(\alpha-\mathrm{Fe}_{2} \mathrm{O}_{3}\right)$ is the most thermodynamically stable iron oxide under ambient conditions [4,5], and it is a promising material because of its advantageous properties for being used as a photocatalyst in photoelectrochemical water splitting [410]. Hematite is an n-type semiconductor with a favorable band gap of $\sim 2.1 \mathrm{eV}$ that absorbs light up to $600 \mathrm{~nm}$, collects up to $\sim 40 \%$ of the solar spectrum energy and has good chemical stability in a wide $\mathrm{pH}$ range. Furthermore, it is an environmentally friendly, non-toxic, abundant and low cost material $[1,3-5,7,8,11-22]$. However, the efficiency of hematite is limited by some drawbacks such as low carrier mobility $\left(10^{-2}\right.$ to $\left.10^{-1} \mathrm{~cm}^{2} \mathrm{~V}^{-1} \mathrm{~s}^{-1}\right)$ and short hole diffusion lengths $(2-4 \mathrm{~nm})$ that lead to high electronhole recombination $[1,7,12-17,19,21]$. Low carrier mobility and short hole diffusion length can cause accumulation of holes on the surface and make the flat band potential more positive. Therefore, a large anodic bias is required to extract the generated photocurrent $[14,23]$. At potentials over $1.3 \mathrm{~V}$ (vs. RHE) the space charge field can separate the photogenerated charges and it is large enough to block the back flow of electrons induced by accumulated holes at the interface. Furthermore, when the applied potential is higher than this value, the faradaic efficiency loss is reduced considerably $[12,24,25]$ 
These issues can be overcome by nanostructuring the material into different nanoarchitectures such as porous structure, tubes, wires or rods $[10,12,18,19,21,23,26]$. One dimensional nanostructures in a preferred orientation of maximum conductivity could improve charge transport, and the thin walls of some nanostructures enhance hole diffusion [1,27]. Nanostructures of iron oxide have been synthetized by different methods such as sol-gel [28], electrodeposition [29], thermal oxidation [30], electrospinning [31] and electrochemical anodization [32]. Among them, electrochemical anodization can produce nanostructures with high control and it has been widely studied in recent years [1,7,11,13,32-34]. Rangaraju [2] synthetized iron oxide nanotubes by electrochemical anodization in ethylene glycol solution containing $\mathrm{NH}_{4} \mathrm{~F}$ and water. Lee [7] also studied nanotubular and nanoporous structures by electrochemical anodization in ethylene glycol-based electrolytes. However, bi-layered hematite nanostructures synthetized by anodization that combine properties of various nanoarchitectures have not been extensively investigated [1].

After anodization, annealing is required in order to obtain a crystalline nanostructure that can be used as a photocatalyst in water splitting. Some authors [11,35] studied different parameters of the anodization process, e.g. anodization temperature, potential, $\mathrm{H}_{2} \mathrm{O}$ concentration, $\mathrm{NH}_{4} \mathrm{~F}$ concentration and annealing temperature. Nevertheless, some aspects like heating rate or annealing atmosphere need to be studied in detail because annealing is one of the most important parameters that determine the physico-chemical properties of the nanostructure [19].

In this study, a novel bi-layered nanostructure consisting of a top nanosphere layer and an underneath nanotubular one was synthetized by electrochemical anodization in an ethylene glycol-based electrolyte containing $\mathrm{NH}_{4} \mathrm{~F}$ and water. This new double layered nanostructure combines the better photocatalytic properties of the nanospheres with the 
better electron transport behavior of the directly grown nanotubular structure from the iron substrate [1]. Different annealing conditions such as temperature, heating rate or annealing atmosphere were studied in order to establish the optimum annealing conditions for this nanostructure. The morphology and electrochemical properties of the nanostructure were characterized by different methods such as Field Emission Scanning Electron Microscopy (FE-SEM), Raman Spectroscopy, Mott-Schottky (MS) analysis and Electrochemical Impedance Spectroscopy (EIS). The morphological and electrochemical properties of the nanostructure have been correlated to the results of the water splitting tests in order to evaluate the performance of this new nanostructure as a photocatalyst for hydrogen production. The results obtained from this study imply an improvement in the performance of iron oxide nanostructures used as photocatalysts in applications such as water splitting.

\section{Experimental}

\subsection{Electrochemical anodization}

Anodization was carried out using $99.9 \%$ pure iron rods $(9.5 \mathrm{~mm}$ in diameter, i.e. an area of $0.7 \mathrm{~cm}^{2}$ was exposed to the electrolyte) as the working electrode, and a platinum foil as a counter electrode. Prior to anodization, the iron rod surface was abraded with 220 to 4000 silicon carbide ( $\mathrm{SiC}$ ) papers in order to obtain a polished finish. After this, the samples were degreased by sonication in ethanol for 2 minutes, followed by rinsing with distilled water and drying in a nitrogen stream. Anodization was performed in a solution of ethylene glycol (EG) containing $0.1 \mathrm{M}$ ammonium fluoride $\left(\mathrm{NH}_{4} \mathrm{~F}\right)$ and 3 vol $\% \mathrm{H}_{2} \mathrm{O}$ at $50 \mathrm{~V}$ for 15 minutes. Current density versus time was continuously 
measured during anodization. After anodization, the as-anodized samples were properly washed with distilled water and dried in a nitrogen stream.

\subsection{Annealing}

Annealing of the as-anodized samples was performed in a tube furnace in order to study different annealing parameters. The evaluated parameters were annealing temperature $\left(300,400\right.$ and $\left.500{ }^{\circ} \mathrm{C}\right)$, heating rate $\left(2,5,15{ }^{\circ} \mathrm{C} / \mathrm{min}\right.$ and nanostructures put directly in the furnace without gradual heating) and annealing atmosphere (air and argon). In all the experiments the samples were cooled within the furnace by natural convection.

\subsection{Characterization}

The morphological aspects of the resulting samples were examined using FE-SEM. The samples were also examined by Raman spectroscopy in order to evaluate their crystalline structure, using a $632 \mathrm{~nm}$ neon laser with $\sim 700 \mu \mathrm{W}$. Additionally, different electrochemical and photoelectrochemical experiments were carried out, such as water splitting tests, EIS measurements and MS analysis.

All the electrochemical and photoelectrochemical experiments were performed in a three-electrode configuration using a saturated $\mathrm{Ag} / \mathrm{AgCl}(3 \mathrm{M} \mathrm{KCl})$ as reference electrode, a platinum tip as counter electrode and the iron oxide nanostructures as working electrode. The area of the nanostructures exposed to the test solution was 0.26 $\mathrm{cm}^{2}$. The measurements were conducted in a $1 \mathrm{M} \mathrm{KOH}$ solution using an Autolab PGSTAT302N potentiostat. The photoelectrochemical measurements were carried out under simulated sunlight conditions AM $1.5\left(100 \mathrm{~mW} \cdot \mathrm{cm}^{-2}\right)$.

Photocurrent density vs. potential measurements were recorded by scanning the potential from $-0.4 \mathrm{~V}_{\mathrm{Ag} / \mathrm{AgCl}}$ to $+0.6 \mathrm{~V}_{\mathrm{Ag} / \mathrm{AgCl}}$ with a scan rate of $2 \mathrm{~m} \cdot \mathrm{s}^{-1}$. Photocurrent 
density transients as a function of the applied potential were recorded by chopped light irradiation $(0.02 \mathrm{~V}$ in the dark and $0.02 \mathrm{~V}$ in the light). The experimentally measured potentials vs. $\mathrm{Ag} / \mathrm{AgCl}$ were converted to the reversible hydrogen electrode (RHE) scale according to Nernst equation (Eq. 1):

$E_{R H E}=E_{A g / A g C l}+0.059 \cdot p H+E_{A g / A g C l}^{0}$

where $E_{R H E}$ is the calculated potential (vs. RHE), $E_{A g / A g C l}$ is the experimentally measured potential (vs. $\mathrm{Ag} / \mathrm{AgCl}$ ), $\mathrm{pH}$ is 14 for the prepared $1 \mathrm{M} \mathrm{KOH}$ solution and $E^{0}{ }_{\mathrm{Ag} / \mathrm{AgCl}}$ is $0.207 \mathrm{~V}$ at $25^{\circ} \mathrm{C}$ for the reference electrode used.

MS plots, in dark and light conditions, were obtained by sweeping the potential from the OCP in the negative direction at $28 \mathrm{mV} \cdot \mathrm{s}^{-1}$ with an amplitude signal of $0.01 \mathrm{~V}$ at a frequency value of $5 \mathrm{kHz}$ in $1 \mathrm{M} \mathrm{KOH}$. EIS experiments were performed in $1 \mathrm{M} \mathrm{KOH}$ at open circuit potential ( $\mathrm{OCP})$ and $0.35 \mathrm{~V}$ (vs. $\mathrm{Ag} / \mathrm{AgCl}$ ) over a frequency range from $100 \mathrm{kHz}$ to $10 \mathrm{mHz}$ with an amplitude of $0.01 \mathrm{~V}$, in both dark and light conditions. Prior to each EIS test, samples were left in the $\mathrm{KOH}$ solution for half an hour (at OCP and $0.35 \mathrm{~V}$, respectively) in order to stabilize them. For the light conditions simulated AM 1.5 illumination was used.

\section{Results and discussion}

\subsection{Process of anodization}

Figure 1a) shows the current density versus time during the anodization process and three stages are clearly observed. In the first stage (I), the current density drops quickly from approximately $130 \mathrm{~mA} \cdot \mathrm{cm}^{-2}$ to less than $25 \mathrm{~mA} \cdot \mathrm{cm}^{-2}$. This decrease is due to the 
formation of a compact oxide layer $\left(\mathrm{Fe}_{2} \mathrm{O}_{3}\right)$ on the iron substrate according to Equation 2, and consequently, resistance increases immediately.

$2 \mathrm{Fe}+3 \mathrm{H}_{2} \mathrm{O} \rightarrow \mathrm{Fe}_{2} \mathrm{O}_{3}+3 \mathrm{H}_{2}$

In the second stage (II), a slow increase in the current density is observed due to the formation of tiny pits on the surface of the compact layer followed by the formation of a nanoporous structure, resulting in a decrease in resistance. This process occurs because the presence of the fluoride ions $\left(\mathrm{F}^{-}\right)$together with the high applied potential during anodization leads to a partial dissolution of the compact $\mathrm{Fe}_{2} \mathrm{O}_{3}$ layer, and consequently a nanoporous structure is formed according to Equation 3.

$\mathrm{Fe}_{2} \mathrm{O}_{3}+12 \mathrm{~F}^{-}+6 \mathrm{H}^{+} \rightarrow 2\left[\mathrm{FeF}_{6}\right]^{3-}+3 \mathrm{H}_{2} \mathrm{O}$
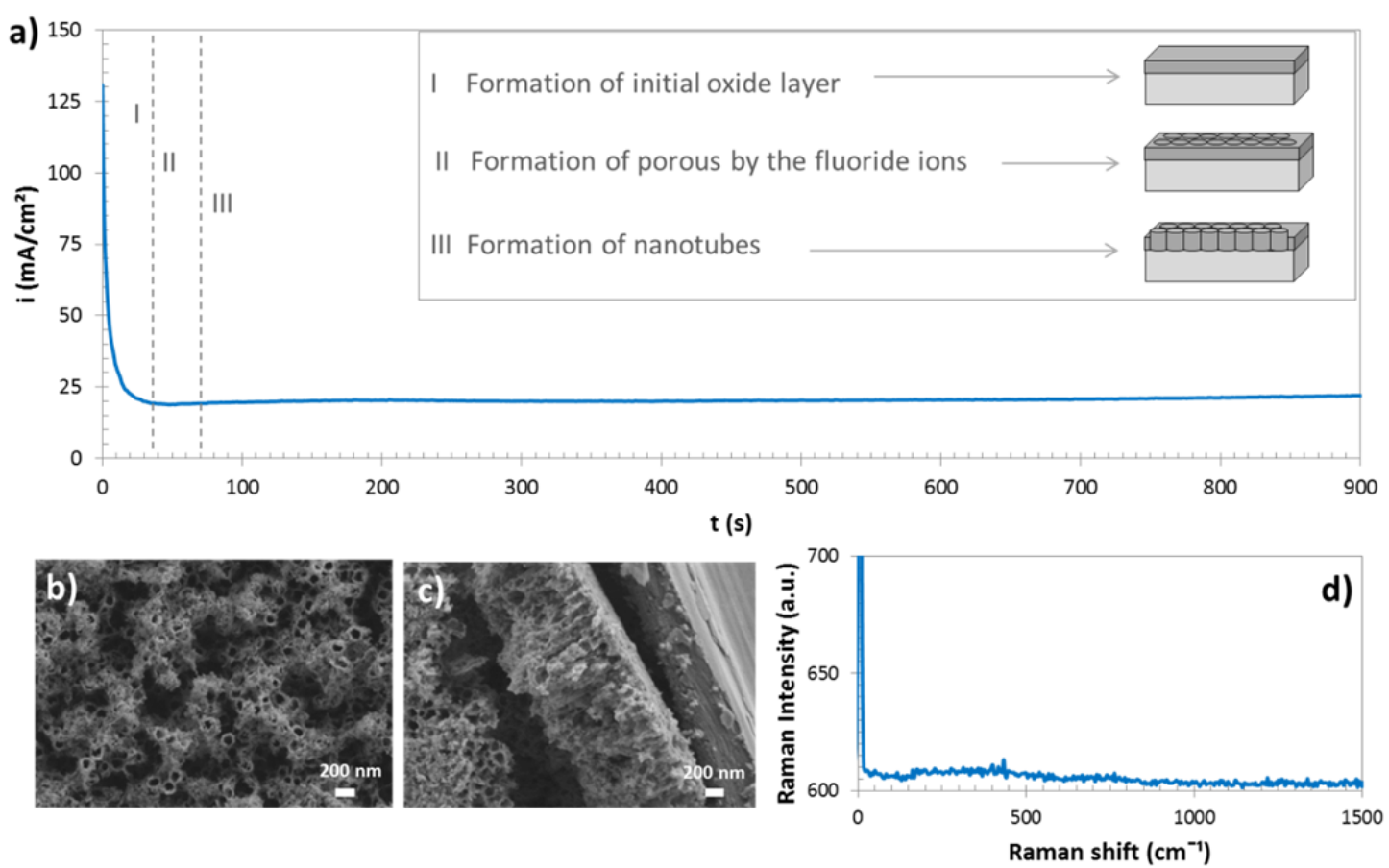

Figure 1. a) Current density versus time during anodization of iron at $50 \mathrm{~V}$ for $15 \mathrm{~min}$ in an ethylene glycol solution containing $0.1 \mathrm{M} \mathrm{NH}_{4} \mathrm{~F}$ and 3\% vol. $\mathrm{H}_{2} \mathrm{O}$. b) FE-SEM top 
view and c) cross section of the nanostructures obtained after the anodization process. d) Raman spectrum of the as-anodized sample.

Finally, in the last stage (III) further dissolution and cation-cation repulsion occurs and the nanoporous structure leads to a nanotubular structure. The formation continues until equilibrium is reached between the formation of the oxide layer and its chemical dissolution by fluoride ions, and then the formation of the tubular nanostructure stops $[27,32,35]$

FE-SEM measurements confirmed the formation of a tubular nanostructure as shown in Fig 1 b) and c), corresponding to the top and cross section of the nanostructure, respectively. The outer diameters of the tubular nanostructure are about $70-85 \mathrm{~nm}$ with a wall thickness of $\sim 30 \mathrm{~nm}$, and the channels are approximately $1150 \mathrm{~nm}$ in length. Furthermore, the Raman spectrum of the as-anodized sample was used to analyze their crystallinity (Fig 1 d)). The Raman spectrum without peaks is in agreement with an amorphous phase; this is because anodization of transition metals, such as iron, generally produces an oxide layer that is amorphous in nature, and becomes crystalline upon annealing $[1,2,11,27,34,36]$.

\subsection{Influence of annealing temperature}

Annealing of the as-anodized samples was performed in a tube furnace under several conditions. Firstly, the samples were annealed in air environment at different temperatures in order to determine the optimum temperature. Figure 2 a) shows the Raman spectra of the samples annealed during 1 hour in air atmosphere at 300, 400 and

$500{ }^{\circ} \mathrm{C}$. The peak at $229 \mathrm{~cm}^{-1}$ is assigned to the $\mathrm{A}_{1 \mathrm{~g}}$ mode of hematite [37] and it appears in the Raman spectra of all heated samples; however its intensity is much higher in the 
sample annealed at $500{ }^{\circ} \mathrm{C}$, which is related to a higher crystallinity of the hematite structure that crystallizes in a rhombohedral structure [38,39]. The peaks observed at $249 \quad \mathrm{~cm}^{-1} \quad\left(\mathrm{E}_{\mathrm{g}}\right), \quad 295 \quad \mathrm{~cm}^{-1} \quad\left(\mathrm{E}_{\mathrm{g}}\right), \quad 414 \quad \mathrm{~cm}^{-1} \quad\left(\mathrm{E}_{\mathrm{g}}\right) \quad$ and $1317 \mathrm{~cm}^{-1}\left(2^{\text {nd }}\right.$ order) in Fig. 2 a) at all the studied temperatures $[37,40,41]$ are also associated with the hematite structure, but the highest Raman intensity is obtained for the sample annealed at $500{ }^{\circ} \mathrm{C}$. Additionally, the sample annealed at $500{ }^{\circ} \mathrm{C}$ has two additional peaks at $500 \mathrm{~cm}^{-1}\left(\mathrm{~A}_{1 \mathrm{~g}}\right)$ and $615 \mathrm{~cm}^{-1}\left(\mathrm{E}_{\mathrm{g}}\right)$ that correspond to the hematite structure. Therefore, temperature increases the crystallinity of the nanostructures and, hence, the sample annealed at $500{ }^{\circ} \mathrm{C}$ has the most crystalline structure. On the other hand, an additional peak appears at $672 \mathrm{~cm}^{-1}\left(\mathrm{~T}_{2 \mathrm{~g}}\right)$ in all annealed samples, which corresponds to the magnetite phase [37]. This indicates that although the predominant crystalline phase in all nanostructures is hematite $\left(\alpha-\mathrm{Fe}_{2} \mathrm{O}_{3}\right)$, their structure contains also magnetite $\left(\mathrm{Fe}_{3} \mathrm{O}_{4}\right)$. 

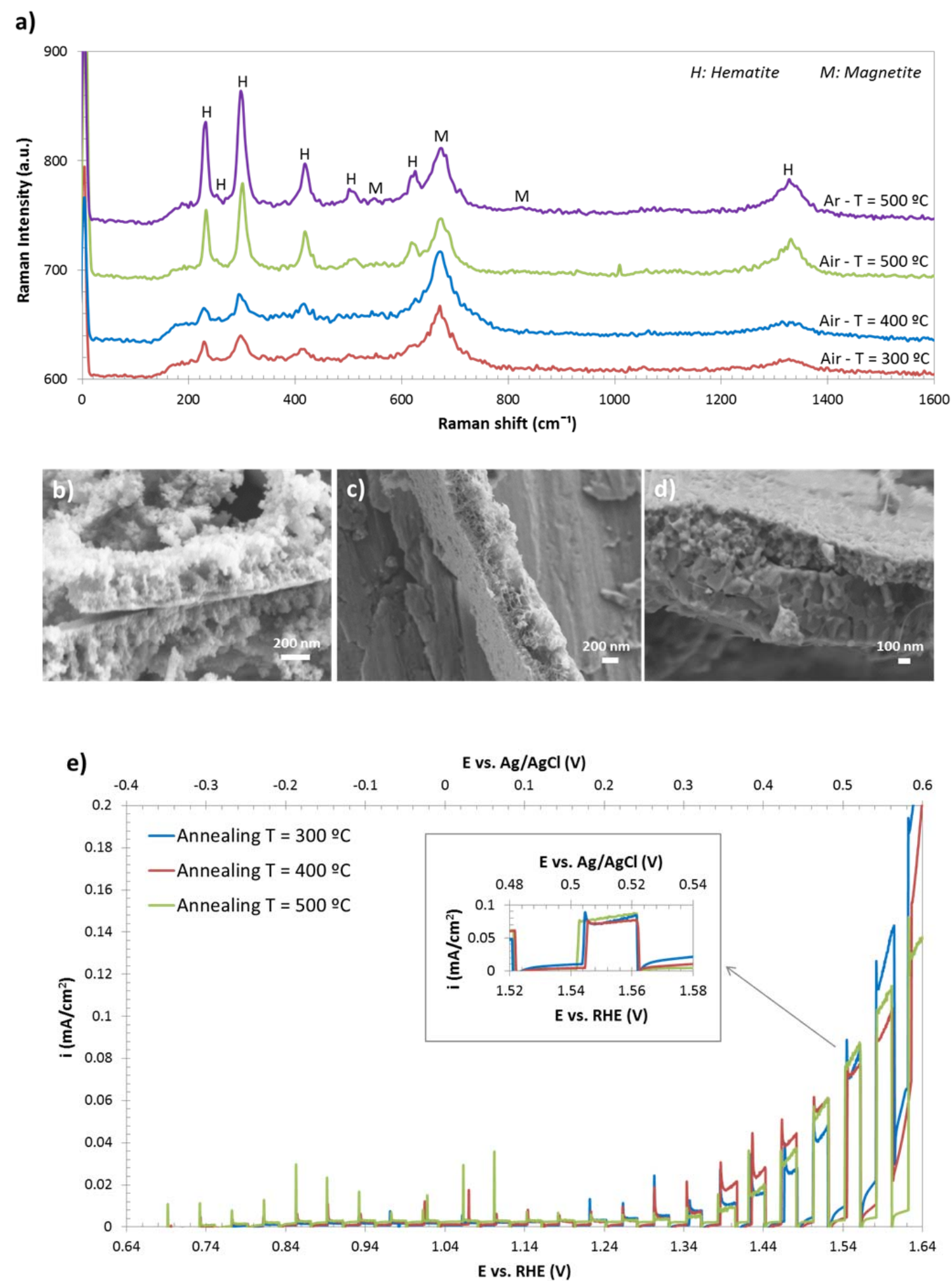

Figure 2. a) Raman spectra of the samples anodized at $50 \mathrm{~V}$ for $15 \mathrm{~min}$ in an ethylene glycol solution containing $0.1 \mathrm{M} \mathrm{NH}_{4} \mathrm{~F}$ and $3 \%$ vol. $\mathrm{H}_{2} \mathrm{O}$ and annealed during 1 hour in air at $300,400,500{ }^{\circ} \mathrm{C}$, and in Argon at $500{ }^{\circ} \mathrm{C}$. b) - d) FESEM cross section views of annealed samples during 1 hour in air atmosphere at 300, 400 and $500{ }^{\circ} \mathrm{C}$ at a heating 
rate of $15^{\circ} \mathrm{C} \cdot \min ^{-1}$, respectively. e) Photocurrent density vs. voltage measurements obtained by applying chopped light irradiation under AM 1.5 illumination in $1 \mathrm{M} \mathrm{KOH}$ for the samples annealed in air (at 300, 400 and $500{ }^{\circ} \mathrm{C}$ ).

The morphology of the nanostructures was evaluated by FE-SEM. Figure 2 b) to d) shows the FE-SEM cross section images of the annealed samples at 300, 400 and 500 ${ }^{\circ} \mathrm{C}$, respectively. According to Fig. 2 b), there is little difference between the sample annealed at $300{ }^{\circ} \mathrm{C}$ and the as-anodized one (Fig $\left.1 \mathrm{c}\right)$ ). The nanostructures in both cases are tubular, but at $300{ }^{\circ} \mathrm{C}$ a sponge-like nanostructure is formed on the top of the tubular nanostructure. When the temperature increases to $400{ }^{\circ} \mathrm{C}$ (Fig. $2 \mathrm{c}$ )) the sponge-like layer on the top of the nanostructure becomes larger and two different layers can be observed. The top of the nanostructure is a sponge-like structure, whereas, below it, a tubular structure can be observed. Finally, when the temperature reaches $500{ }^{\circ} \mathrm{C}$ (Fig. 2 d)), there is a significant change, because the entire nanostructure becomes more compact and the two layers are clearly differentiated. The sponge-like layer that appeared at $400{ }^{\circ} \mathrm{C}$ becomes a layer with nanospheres at $500{ }^{\circ} \mathrm{C}$ and hence, a new bilayered structure with nanospherical and nanotubular layers is obtained.

Fig. 2 e) shows the photoelectrochemical water splitting performance under simulated sunlight AM 1.5 for the samples annealed at 300, 400 and $500{ }^{\circ} \mathrm{C}$. It is noticeable that the sample annealed at $300{ }^{\circ} \mathrm{C}$ presents the lowest photocurrent density in comparison with the other ones. The samples annealed at $400{ }^{\circ} \mathrm{C}$ and $500{ }^{\circ} \mathrm{C}$ have very similar performance in terms of photocurrent transient vs. potential curves. However, at higher potentials $\left(>1.52 \mathrm{~V}\right.$ (vs. RHE)) the sample annealed at $500{ }^{\circ} \mathrm{C}$ shows a better performance, achieving a photocurrent density of $0.078 \mathrm{~mA} \cdot \mathrm{cm}^{-2}$ at $1.54 \mathrm{~V}$ (vs. RHE). In addition, it is noteworthy that at such potential, the sample annealed at $500{ }^{\circ} \mathrm{C}$ shows 
the lowest recombination rate (see inset of Fig. 2 e)). This is due to the fact that there is an initial slow decay of the photocurrent density until the steady-state value is reached, which is in agreement with a loss of the photogenerated electrons that could be associated with a slow recombination process [1].

The better water splitting performance of the sample annealed at $500{ }^{\circ} \mathrm{C}$ is attributed to the new bi-layered nanostructure together with the combination of hematite and some amount of magnetite in its crystalline structure. On the one hand, the bi-layered nanostructure combines the better photocatalytic properties of the nanospheres with the better electron transport behavior of the directly grown nanotubular structure from the iron substrate [1]. On the other hand, the amount of magnetite in the nanostructure enhances its electrical conductivity. This is because the magnetite (with a low band-gap of $\sim 0.1 \mathrm{eV}$ ) has an inversed spinel structure and the electron and holes hopping between the $\mathrm{Fe}^{2+}$ and $\mathrm{Fe}^{3+}$ ions located at the octahedral sites result in a higher conductivity of magnetite in comparison with hematite $[27,36,42-44]$.

\subsection{Influence of heating rate}

After determining the optimum temperature, different heating rates up to $500{ }^{\circ} \mathrm{C}$ were studied for the air atmosphere. All the samples were cooled down within the furnace by natural convection. Fig. 3 shows the photocurrent density vs. potential measurements for the samples annealed during 1 hour at $500{ }^{\circ} \mathrm{C}$ at heating rates of $2{ }^{\circ} \mathrm{C} \cdot \min ^{-1}, 15^{\circ} \mathrm{C}$. $\min ^{-1}$ and directly put in the furnace when the temperature of $500{ }^{\circ} \mathrm{C}$ was reached. The sample that was directly put in the furnace do not show photocatalytic activity to the chopped light, probably due to the absence of an homogeneous and well defined nanostructure because the abrupt change in temperature resulted in spalling off of the oxide layer as it is shown in the FE-SEM top view image in inset of Fig. 3. FE-SEM 
evaluation also shows that for samples annealed at 2 and $15{ }^{\circ} \mathrm{C} \cdot \mathrm{min}^{-1}$ there are no differences in the morphology of the nanostructure, consisting in both cases of a bilayered structure with nanospherical and nanotubular layers (see Fig. 2 d) as an illustration).

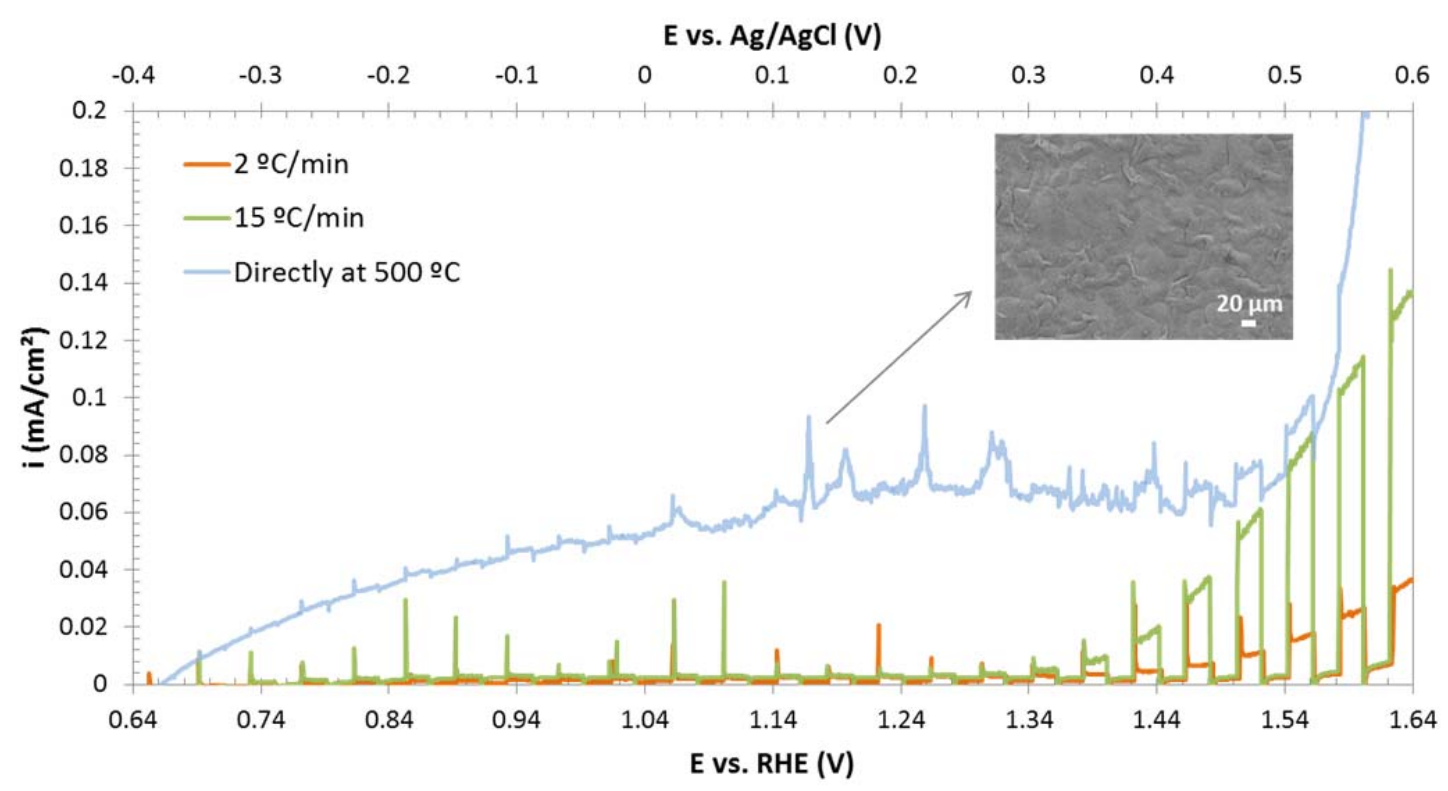

Figure 3. Photocurrent density vs. voltage measurements obtained by applying chopped light irradiation under $\mathrm{AM} 1.5$ illumination in $1 \mathrm{M} \mathrm{KOH}$ for the samples annealed during 1 hour in air atmosphere at $500{ }^{\circ} \mathrm{C}$ at heating rates of $2{ }^{\circ} \mathrm{C} \cdot \min ^{-1}, 15^{\circ} \mathrm{C} \cdot \min ^{-1}$ and directly put in the furnace when reached $500{ }^{\circ} \mathrm{C}$, and FE-SEM top view of the sample put directly in the furnace at $500{ }^{\circ} \mathrm{C}$.

Both nanostructures annealed at heating rates of 2 and $15^{\circ} \mathrm{C} \cdot \min ^{-1}$ show some photocatalytic activity but the sample annealed at $15^{\circ} \mathrm{C} \cdot \mathrm{min}^{-1}$ achieve higher photocurrent densities as Fig. 3 shows, being the maximum photocurrent density $0.078 \mathrm{~mA} \cdot \mathrm{cm}^{-2}$ at $1.54 \mathrm{~V}$ (vs. RHE). This better performance could be attributed to the fact that at faster heating rates, the structure crystallizes rapidly and some lattice 
structural defects such as oxygen vacancies (which are compensated by $\mathrm{Fe}^{2+}$ ions to guarantee electroneutrality) are introduced in the structure [36,45-47]. These defects are located between the valence and the conduction band so they act as donor states decreasing surface recombination centers and enhancing charge transfer rate. Consequently, the electrical conductivity of the nanostructure is increased and, hence, the water splitting performance of the nanostructure is improved $[1,2,48,49]$.

\subsection{Influence of annealing atmosphere}

In order to study the influence of a non-oxidizing atmosphere, different experiments were carried out heating in argon at different heating rates. The studied heating rates were 2,5 and $15^{\circ} \mathrm{C} \cdot \mathrm{min}^{-1}$. Since the sample annealed in air that was directly put in the furnace when the temperature was reached resulted in spalling of the oxide layer, in the study of the argon atmosphere this heating rate was not carried out. However, a new heating rate $\left(5{ }^{\circ} \mathrm{C} \cdot \mathrm{min}^{-1}\right)$ was studied in order to evaluate if an intermediate value between 2 and $15^{\circ} \mathrm{C} \cdot \mathrm{min}^{-1}$ shows better or worse performance in this case.

Fig. 4 shows the photocurrent density versus time measurements in argon atmosphere at the studied heating rates. The samples annealed at 2 and $5{ }^{\circ} \mathrm{C} \cdot \min ^{-1}$ show very low photocatalytic activity in comparison with the sample annealed at $15{ }^{\circ} \mathrm{C} \cdot \mathrm{min}^{-1}$, the latter achieving a photocurrent density of $\sim 0.143 \mathrm{~mA} \cdot \mathrm{cm}^{-2}$ at $1.54 \mathrm{~V}$ (vs. RHE). Comparing both atmospheres at the optimum heating rate of $15^{\circ} \mathrm{C} \cdot \min ^{-1}$ (Fig. 3 and Fig. 4), it is noticed that the samples annealed in argon atmosphere show a higher photocurrent density than those annealed in an air atmosphere that achieved $\sim 0.078 \mathrm{~mA}$ $\cdot \mathrm{cm}^{-2}$ at $1.54 \mathrm{~V}$ (vs. RHE). Additionally, in argon atmosphere the photocurrent densities of the nanostructures are considerably higher even at lower potentials, for instance, in argon at $0.2 \mathrm{~V}$ (vs. RHE) a photocurrent density of $\sim 0.0256 \mathrm{~mA} \cdot \mathrm{cm}^{-2}$ is achieved 
whereas in air at $0.4 \mathrm{~V}$ (vs. RHE) a photocurrent of $\sim 0.0204 \mathrm{~mA} \cdot \mathrm{cm}^{-2}$ is reached. This better performance for the samples annealed in argon is due to the fact that annealing in non-oxidizing atmospheres, such as argon, promotes the formation of magnetite in the nanostructure, and oxygen vacancies which improve the electrical conductivity of the nanostructure are incorporated $[1,2,36,42,43]$. In general terms, oxygen vacancies are formed by the transfer of an oxygen atom on a normal site to the gaseous state according to Equation 4.

$O_{O}^{x} \rightarrow v_{O}^{\bullet \bullet}+2 e^{-}+\frac{1}{2} O_{2}(g)$

If the annealing atmosphere is non-oxidizing (such as argon), according to Le Chatelier's principle the reaction becomes favorable in the right direction and this results in favouring the formation of oxygen vacancies $[1,2,36]$.

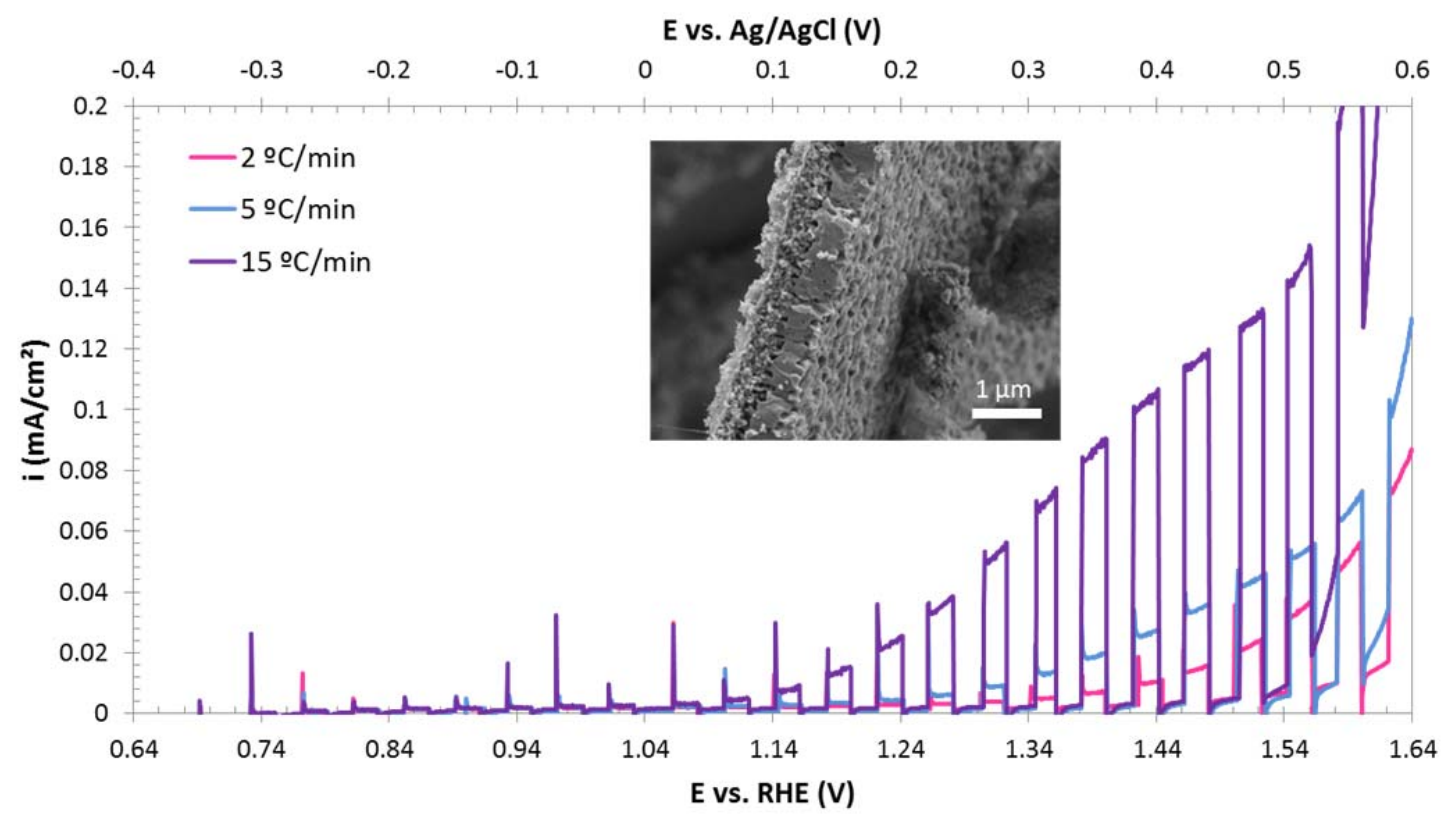

Figure 4. Photocurrent density vs. voltage measurements obtained by applying chopped light irradiation under $\mathrm{AM} 1.5$ illumination in $1 \mathrm{M} \mathrm{KOH}$ for the samples annealed 
during 1 hour in $\operatorname{argon}$ atmosphere at $500{ }^{\circ} \mathrm{C}$ at heating rates of 2,5 and $15{ }^{\circ} \mathrm{C} \cdot \min ^{-1}$ and FE-SEM cross sectional view of the obtained nanostructure.

According to the presence of magnetite, the Raman spectra of the sample annealed in argon at $15{ }^{\circ} \mathrm{C} \cdot \min ^{-1}$ (see Fig. 2 a)) shows two additional peaks corresponding to magnetite at $554 \mathrm{~cm}^{-3}$ and at $\sim 820 \mathrm{~cm}^{-3}[37,50]$. This larger amount of magnetite in the nanostructure results in a higher electrical conductivity. As a result, the improvement in the electrical conductivity leads to better photocatalytic properties of the nanostructure for photoelectrochemical water splitting.

FE-SEM evaluation revealed that there are no differences in the nanostructure for the samples annealed in argon at the different heating rates; the inset of Fig. 4 shows an example of their morphology. According to Fig. 4, the morphology of the nanostructure is the same as the one obtained in air atmosphere at $500{ }^{\circ} \mathrm{C}$ (Fig. $2 \mathrm{~d}$ )), which consists of a bi-layered structure with nanospherical and nanotubular layers.

\subsection{Mott-Schottky analysis}

Mott-Schottky plots were carried out in dark and light conditions at a frequency value of $5 \mathrm{kHz}$. The experiments were carried out in $1 \mathrm{M} \mathrm{KOH}$ by sweeping the potential from the OCP in the negative direction at $28 \mathrm{mV} \cdot \mathrm{s}^{-1}$ with an amplitude signal of 0.01 V. Fig. 5 shows the MS plots obtained for the samples annealed during 1 hour at $500{ }^{\circ} \mathrm{C}$ for both atmospheres (air and argon) with and without illumination. A positive slope corresponding to an n-type semiconductor behaviour is observed [1,51]. The lower slopes of the linear region of MS plots indicate a higher electron donor density. Equation 5 is used for an n-type semiconductor [52-54]. 
$\frac{1}{C_{S C}^{2}}=\left(\frac{2}{e \cdot \varepsilon_{0} \cdot \varepsilon_{r} \cdot N_{D}}\right) \cdot\left(U-U_{F B}-\frac{k \cdot T}{e}\right)$

where $C_{S C}$ is the space charge layer capacitance, $e$ the electron charge $\left(1.60 \cdot 10^{-19} \mathrm{C}\right), \varepsilon_{0}$ the vacuum permittivity $\left(8.85 \cdot 10^{-14} \mathrm{~F} \cdot \mathrm{cm}^{-1}\right), \varepsilon_{r}$ the dielectric constant (a value of 80 is assumed for the nanostructure [55-57]), $N_{D}$ the donor density, $U$ the applied potential, $U_{F B}$ the flat-band potential, $k$ the Boltzmann constant $\left(1.38 \cdot 10^{-23} \mathrm{~J} \cdot \mathrm{K}^{-1}\right)$ and $T$ the absolute temperature.

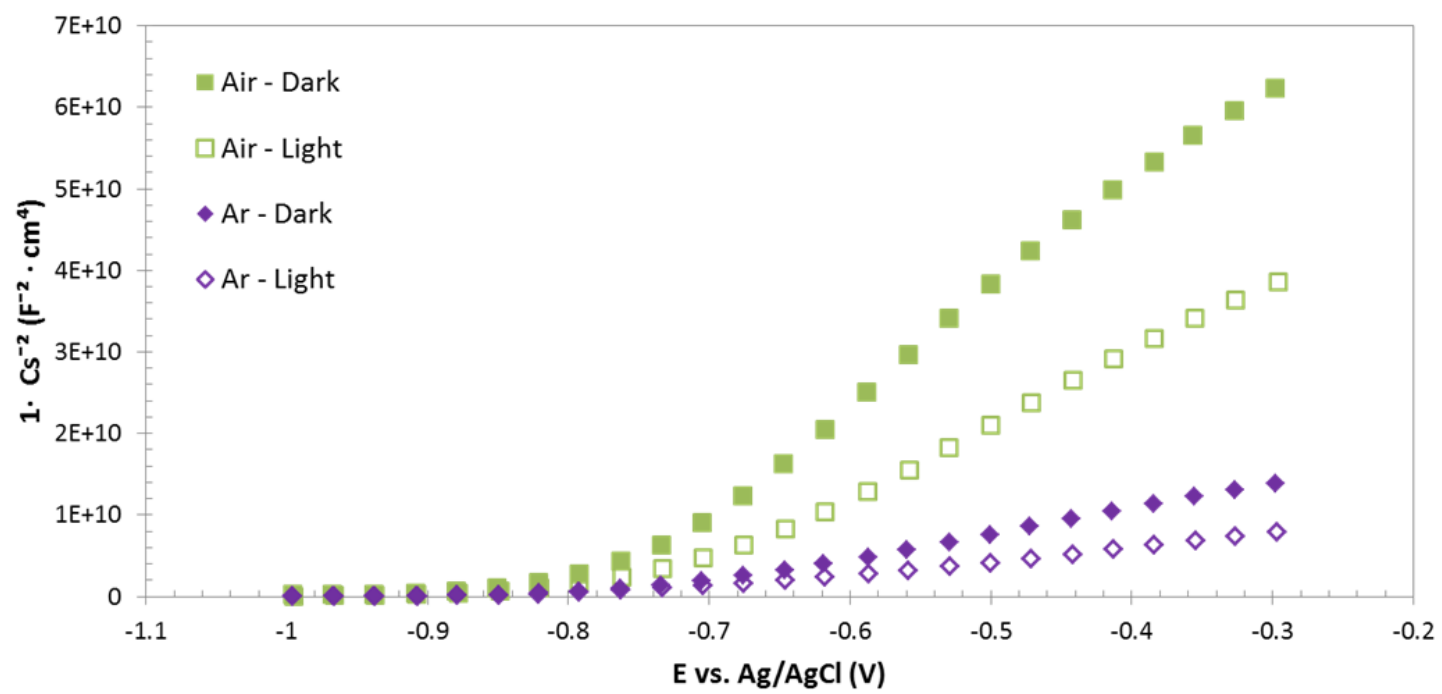

Figure 5. Mott-Schottky plots of the samples annealed during 1 hour in air and argon atmospheres at $500{ }^{\circ} \mathrm{C}$ at a heating rate of $15^{\circ} \mathrm{C} \cdot \mathrm{min}^{-1}$, under dark and light conditions in $1 \mathrm{M} \mathrm{KOH}$. Simulated AM 1.5 illumination was used for the light conditions.

In order to determine the donor density, $N_{D}$, the linear regions of the MS plots were used and the results are shown in Table 1. As it was expected, the values obtained under illumination are higher than those obtained in dark conditions in both atmospheres. This is because illumination generates electron-hole pairs and consequently, the donor density of the samples increases with light. The donor density values are of the order of 
$10^{19} \mathrm{~cm}^{-3}$, but are much higher for the samples annealed in argon than in air. This increase could be due to the increase of the amount of magnetite and oxygen vacancies for samples annealed in non-oxidizing atmospheres such as argon [36,58]. This is in agreement with the Raman spectra of the samples (Fig. 2 a)) and with the photocurrent density versus time measurements (Fig. 3 and Fig. 4), i.e. better in argon than in air. Therefore, annealing in a non-oxidizing atmosphere can increase the oxygen vacancies and the electrical conductivity of the nanostructure and hence, the water splitting performance of the nanostructure improves.

The flat-band potential $\left(U_{F B}\right)$ is the potential needed to be applied to the semiconductor in order to reduce band bending to zero, i.e. the potential at which there is no depleted space charge layer. This flat-band potential is related to the applied external potential $\left(U_{A}\right)$ and to the potential difference in the space charge region of the semiconductor when it is in contact with the electrolyte $\left(\Delta \phi_{S C}\right)$, according to Equation 6.

$\Delta \phi_{S C}=U_{A}-U_{F B}$

For a constant applied external potential, when $U_{F B}$ increases and becomes more negative $\Delta \phi_{S C}$ increases, so the electric field within the space charge region is higher and consequently, the recombination of the photogenerated electron-holes decreases $[51,59]$.

The flat-band potential was calculated from the intercept of the straight line in the MS plots with the potential axis. Table 1 shows that the flat band potentials are similar, of the order of $\sim-0.7 \mathrm{~V}$ for all the samples, so the recombination of the photogenerated electron-holes is similar for both atmospheres. In spite of this fact, the much higher donor density of the samples annealed in argon results in better photocatalytic properties of the nanostructure in applications such as water splitting. 


\subsection{Electrochemical Impedance Spectroscopy}

EIS experiments were performed at $\mathrm{OCP}$ and $0.35 \mathrm{~V}$ (vs. $\mathrm{Ag} / \mathrm{AgCl}$ ) in both dark and light conditions over a frequency range from $100 \mathrm{kHz}$ to $10 \mathrm{mHz}$ with an amplitude of 0.01 V. Figure 6 shows the Nyquist (Fig. 6 a)-b)), Bode-phase (Fig. 6 c)-d)) and Bodemodulus (Fig. 6 c)-d)) plots for the samples annealed both in air and argon atmospheres.
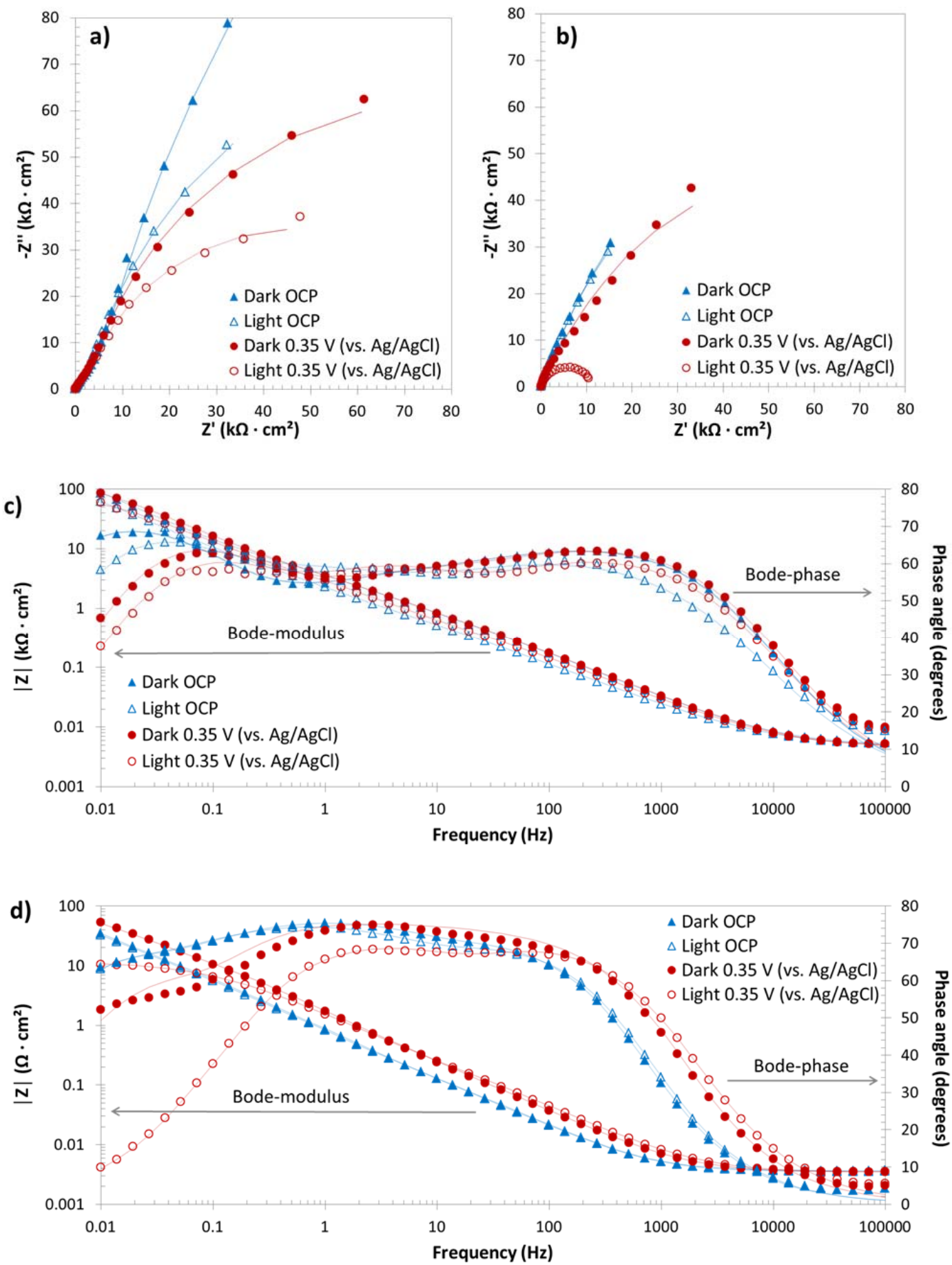
Figure 6. Experimental Nyquist plots of the samples annealed in air a) and in argon b), and Bode-modulus and Bode-phase plots of the samples annealed in air c) and argon d), under dark and light conditions in $1 \mathrm{M} \mathrm{KOH}$. Simulated AM 1.5 illumination was used for the light conditions.

Figure 6 a)-b) reveals that the impedance decreases in light conditions regardless of the annealing atmosphere, which could be attributed to the photogenerated charge carriers [1]. It is noticeable that the impedances are lower for the samples annealed in argon atmosphere than in air, this is due to the fact that annealing in a non-oxidizing atmosphere increases the number of oxygen vacancies, which enhances conductivity and as a result, impedance decreases. This is in agreement with the Mott-Scottky results (Table 1) that show a higher donor density for the samples annealed in argon. This in turn results in a better conductivity and consequently, a better water splitting performance (Fig. 4).

Table 1. Values of donor density $\left(\mathrm{N}_{\mathrm{D}}\right)$ and flat-band potential $\left(\mathrm{U}_{\mathrm{FB}}\right)$ for the samples annealed during 1 hour in air and argon atmospheres at $500{ }^{\circ} \mathrm{C}$ at a heating rate of $15{ }^{\circ} \mathrm{C}$ - $\min ^{-1}$, under dark and light conditions in $1 \mathrm{M} \mathrm{KOH}$. Simulated AM 1.5 illumination was used for the light conditions.

\begin{tabular}{llll}
\hline $\begin{array}{l}\text { Annealing } \\
\text { atmosphere }\end{array}$ & Conditions & $\mathbf{N}_{\mathrm{D}}\left(\cdot \mathbf{1 0}^{\mathbf{1 9}} \mathbf{c m}^{-\mathbf{3}}\right)$ & $\mathbf{U}_{\mathrm{FB}}(\mathrm{V}$ vs. Ag/AgCl) \\
\hline Air & Dark & $1.24 \pm 0.45$ & $-0.77 \pm 0.04$ \\
Air & Light & $1.92 \pm 0.58$ & $-0.73 \pm 0.06$ \\
Argon & Dark & $5.57 \pm 0.53$ & $-0.74 \pm 0.05$ \\
Argon & Light & $9.78 \pm 0.58$ & $-0.74 \pm 0.07$ \\
\hline
\end{tabular}


The real component of the impedance in the Nyquist plot is attributed predominantly to the charge transfer resistance $[1,36]$. Figure $6 a$ a)-b) shows that, under illumination, the charge transfer slightly decreases, whereas when an external potential is applied the charge transfer decreases significantly, which indicates that the influence of potential is higher than the influence of illumination. Furthermore, under illumination and with applied potential the real and imaginary components of the impedance are significantly lower than in the other cases, indicating the influence of the potential in the charge separation under illumination [1].

Bode-phase plots show three differentiated time constants for the samples annealed in air atmosphere (Fig. 6 c)); but they only shows two time constants for the nanostructures annealed in argon (Figure $6 \mathrm{~d}$ )), as a result of the superposition of two of them at low frequencies and another one at high frequencies, suggesting in both cases (argon and air) the presence of three time constants. Besides, Bode-modulus plots (Fig. 6 c)-d)) indicate that the impedance modulus decreases under illumination. Additionally, the resistance associated with the solution $\left(R_{S}\right)$, which corresponds to the impedance at high frequencies, is similar regardless the annealing atmosphere and conditions.

EIS experimental data can be fitted to an electrical equivalent circuit (Figure 7). The equivalent circuit consists of a resistive element corresponding to the resistance of the solution $\left(R_{S}\right)$, two groups of resistance and constant phase elements (R-CPE) in parallel corresponding to the $\alpha-\mathrm{Fe}_{2} \mathrm{O}_{3}$ bi-layered nanostructure with a nanosphere top layer $\left(R_{1^{-}}\right.$ $\left.C P E_{1}\right)$ and an underneath nanotubular one $\left(R_{2}-C P E_{2}\right)$, and, finally, another $R_{3}-C P E_{3}$ group in series corresponding to the compact layer of $\mathrm{Fe}_{2} \mathrm{O}_{3}$ that remains unchanged beneath the nanostructure upon annealing. Constant phase elements (CPE) have been 
used instead of pure capacitors to account for frequency dispersion and non-ideality [51].

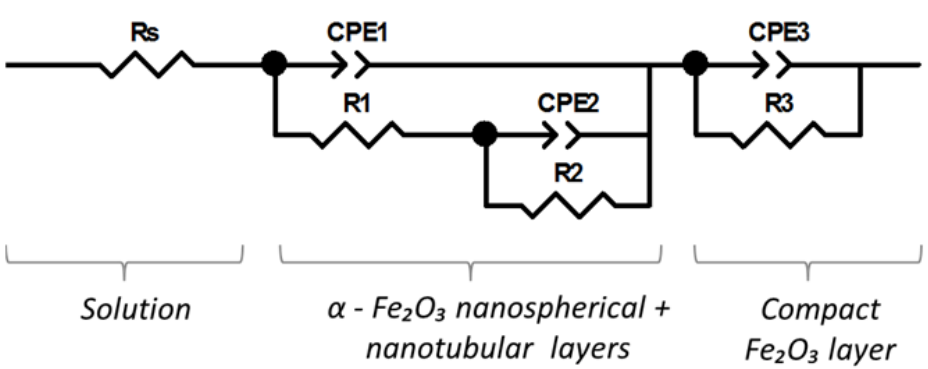

Figure 7. Electrical equivalent circuit used to simulate the experimental EIS data obtained for the synthetized nanostructures.

Table 2 shows the resistance values of the equivalent circuit. Chi-squared values $\left(\chi^{2}\right)$ were used to evaluate the quality of data fitting to the proposed equivalent circuit. $\chi^{2}$ values were of the order of $10^{-3}$ or lower, which indicates the suitability of the equivalent circuit. Regarding $R_{S}$, the values are similar for all the studied conditions $(\sim 4$ $\Omega \cdot \mathrm{cm}^{2}$ ). Besides, $R_{1}$ values are lower than $R_{2}$ values indicating that the nanosphere layer possesses higher electrical conductivity. Moreover, $R_{3}$, which corresponds to the resistance of the compact layer of $\mathrm{Fe}_{2} \mathrm{O}_{3}$, presents the highest values because the conductivity is lower than that for the nanostructures. This could be related to the lower porosity of the compact layer with respect to the above nanostructure which offers less resistance. Under illumination and applying an external bias the resistance decreases significantly. Illumination promotes the formation of photogenerated charge carriers which results in a decrease in charge transfer resistance. Furthermore, the application of an external bias significantly affects charge separation under illuminated conditions [1]. Accordingly, resistance decreases when a potential of $0.35 \mathrm{~V}$ (vs. $\mathrm{Ag} / \mathrm{AgCl}$ ) is applied 
under illumination, achieving the lowest resistance values for the sample annealed in argon atmosphere $\left(R_{1} \sim 46 \Omega \cdot \mathrm{cm}^{-2}, R_{2} \sim 1.3 \mathrm{k} \Omega \cdot \mathrm{cm}^{2}\right.$ and $\left.R_{3} \sim 10.3 \mathrm{k} \Omega \cdot \mathrm{cm}^{2}\right)$. That is, annealing in non-oxidizing atmosphere can enhance conductivity and consequently, reduce resistance [1,36]. In fact, Raman spectroscopy (Fig. 2 a)) shows that the nanostructures annealed in argon present more magnetite phase than the other ones, which results in higher conductivity. Water splitting tests (Fig. 4) and Mott-Schottky plots (Fig. 5) also agree with these results, indicating that the nanostructures annealed in argon achieve the best photocurrent density values and present the highest donor density, respectively, i.e. they possess the best photocatalytic properties.

Table 2. Resistance values in the equivalent circuit for the samples annealed during 1 hour in air and argon atmospheres at $500{ }^{\circ} \mathrm{C}$ at a heating rate of $15{ }^{\circ} \mathrm{C} \cdot \mathrm{min}^{-1}$, under dark and light conditions in $1 \mathrm{M} \mathrm{KOH}$. Simulated AM 1.5 illumination was used for the light conditions.

\begin{tabular}{|c|c|c|c|c|c|}
\hline Conditions & $\begin{array}{l}R_{S} \\
\left(\Omega \cdot \mathrm{cm}^{2}\right)\end{array}$ & $\begin{array}{l}R_{1} \\
\left(\Omega \cdot \mathrm{cm}^{2}\right)\end{array}$ & $\begin{array}{l}R_{2} \\
\left(\mathrm{k} \Omega \cdot \mathrm{cm}^{2}\right)\end{array}$ & $\begin{array}{l}R_{3} \\
\left(\mathrm{k} \Omega \cdot \mathrm{cm}^{2}\right)\end{array}$ & $\begin{array}{l}\chi^{2} \\
\left(\cdot 10^{-3}\right)\end{array}$ \\
\hline Air - Dark & $4.9 \pm 0.8$ & $915.6 \pm 32.3$ & $4.3 \pm 1.9$ & $591.3 \pm 56.3$ & 0.9 \\
\hline Air - Light OCP & $4.6 \pm 0.5$ & $1220.0 \pm 101.5$ & $3.0 \pm 1.2$ & $175.2 \pm 73.2$ & 1.1 \\
\hline Air - Dark 0.35 V (vs. Ag/AgCl) & $4.5 \pm 1.1$ & $770.4 \pm 82.5$ & $2.6 \pm 0.9$ & $152.4 \pm 80.1$ & 0.8 \\
\hline Air - Light 0.35 V (vs. Ag/AgCl) & $4.5 \pm 0.5$ & $542.8 \pm 40.6$ & $1.4 \pm 0.2$ & $90.7 \pm 12.2$ & 1.1 \\
\hline $\mathrm{Ar}-\mathrm{D}$ & $3.6 \pm$ & $350.3 \pm 3$ & $5.3 \pm 0.4$ & $137.2 \pm 25.9$ & 0.4 \\
\hline Ar - Light OCP & $3.5 \pm 0.8$ & $198.0 \pm 42.5$ & $4.3 \pm 0.4$ & $135.5 \pm 31.2$ & 0.4 \\
\hline Ar - Dark $0.35 \mathrm{~V}$ & $3.5 \pm 0.7$ & $76.8 \pm 25.1$ & $2.5 \pm 0.8$ & $126.7 \pm 52.4$ & 2.7 \\
\hline Ar - Light $0.35 \mathrm{~V}$ (vs. Ag/AgCl) & $3.4 \pm 0.8$ & $46.0 \pm 12.2$ & $1.3 \pm 0.4$ & $10.3 \pm 2.1$ & 0.3 \\
\hline
\end{tabular}

It is noteworthy to indicate that a multivariable study to evaluate the interactions among all the variables (temperature, heating rate and atmosphere) would be carried out in future works. The multivariate study (experimental design, chemometrics) takes into 
account all the relevant variables and their interactions in order to find the optimum conditions for the proper functioning of the studied material. In fact, some authors used the multivariate method in their studies in the solar energy field [60-62].

\section{Conclusions}

In the present study, a new $\alpha-\mathrm{Fe}_{2} \mathrm{O}_{3}$ bi-layered nanostructure consisting of a top nanosphere layer and an underneath nanotubular one was synthetized by electrochemical anodization in an ethylene glycol solution containing $0.1 \mathrm{M} \mathrm{NH}_{4} \mathrm{~F}$ and $3 \%$ vol. $\mathrm{H}_{2} \mathrm{O}$. After anodization, different annealing parameters were studied (temperature, heating rate and atmosphere), obtaining predominantly an hematite phase in the nanostructure with some amount of magnetite as Raman spectra reveals. FE-SEM images show that the morphology is limited predominantly by the temperature, obtaining the bi-layered nanostructure at $500{ }^{\circ} \mathrm{C}$.

Water splitting performance was evaluated and the highest photocurrent density of $0.143 \mathrm{~mA} \cdot \mathrm{cm}^{-2}$ at $1.54 \mathrm{~V}$ (vs. RHE) was for the nanostructure annealed in argon at 500 ${ }^{\circ} \mathrm{C}$ with a heating rate of $15^{\circ} \mathrm{C} \cdot \min ^{-1}$. This is in agreement with the Mott-Schottky plots that indicate that this nanostructure possesses the highest donor density, which increases its conductivity. Furthermore, Electrochemical Impedance Spectroscopy demonstrates the better photocatalytic performance of this nanostructure under illumination with an external applied potential of $0.35 \mathrm{~V}$ (vs. $\mathrm{Ag} / \mathrm{AgCl}$ ). Then, the synthetized bi-layered nanostructure under the optimum annealing conditions possesses properties that make it an efficient photocatalyst for applications such as water splitting. 
Acknowledgements: The authors would like to express their gratitude for the financial support to the Ministerio de Economía y Competitividad (Reference: BES-2014068713, Project Code: CTQ2013-42494-R), for its help in the Laser Raman Microscope acquisition (UPOV08-3E-012) and for the co-finance by the European Social Fund.

\section{REFERENCES}

[1] R.R. Rangaraju, A. Panday, K.S. Raja, M. Misra. Nanostructured anodic iron oxide film as photoanode for water oxidation. J. Phys. D. Appl. Phys. 42 (2009) 135303. doi:10.1088/0022-3727/42/13/135303.

[2] R.R. Rangaraju, K.S. Raja, a. Panday, M. Misra. An investigation on room temperature synthesis of vertically oriented arrays of iron oxide nanotubes by anodization of iron. Electrochim. Acta. 55 (2010) 785-793. doi:10.1016/j.electacta.2009.07.012.

[3] B.D. Chernomordik, H.B. Russell, U. Cvelbar, J.B. Jasinski, V. Kumar, T. Deutsch, et al.

Photoelectrochemical activity of as-grown, $\alpha-\mathrm{Fe}_{2} \mathrm{O}_{3}$ nanowire array electrodes for water splitting. Nanotechnology. 23 (2012) 194009. doi:10.1088/0957-4484/23/19/194009.

[4] K. Sivula, F. Le Formal, M. Grätzel.

Solar Water Splitting: Progress Using Hematite $\left(\alpha-\mathrm{Fe}_{2} \mathrm{O}_{3}\right)$ Photoelectrodes. ChemSusChem. 4 (2011) 432-449. doi:10.1002/cssc.201000416.

[5] M. Mishra, D.-M. Chun. $\alpha-\mathrm{Fe}_{2} \mathrm{O}_{3}$ as a photocatalytic material: A review. Appl. Catal. A Gen. 498 (2015) 126-141. doi:10.1016/j.apcata.2015.03.023.

[6] L. Wang, C.-Y. Lee, R. Kirchgeorg, H. Hildebrand, J. Müller, E. Spiecker, et al. A significant cathodic shift in the onset potential of photoelectrochemical water splitting for hematite nanostructures grown from $\mathbf{F e}-\mathrm{Si}$ alloys. Mater. Horizons. 1 (2014) 344. doi:10.1039/c3mh00173c.

[7] C.-Y. Lee, L. Wang, Y. Kado, M.S. Killian, P. Schmuki. Anodic nanotubular/porous hematite photoanode for solar water splitting: substantial effect of iron substrate purity. ChemSusChem. 7 (2014) 934-40. doi:10.1002/cssc.201300603. 
[8] Z. Zhang, M.F. Hossain, T. Takahashi.

Fabrication of shape-controlled $\alpha-\mathrm{Fe}_{2} \mathrm{O}_{3}$ nanostructures by sonoelectrochemical anodization for visible light photocatalytic application. Mater. Lett. 64 (2010) 435-438. doi:10.1016/j.matlet.2009.10.071.

[9] B.C. Fitzmorris, J.M. Patete, J. Smith, X. Mascorro, S. Adams, S.S. Wong, et al. Ultrafast transient absorption studies of hematite nanoparticles: The effect of particle shape on exciton dynamics.

ChemSusChem. 6 (2013) 1907-1914. doi:10.1002/cssc.201300571.

[10] B. Klahr, S. Gimenez, F. Fabregat-Santiago, T. Hamann, J. Bisquert. Water oxidation at hematite photoelectrodes: The role of surface states. J. Am. Chem. Soc. 134 (2012) 4294-4302. doi:10.1021/ja210755h.

[11] B. Sarma, A.L. Jurovitzki, Y.R. Smith, R.S. Ray, M. Misra. Influence of annealing temperature on the morphology and the supercapacitance behavior of iron oxide nanotube (Fe-NT).

J. Power Sources. 272 (2014) 766-775. doi:10.1016/j.jpowsour.2014.07.022.

[12] J.Y. Kim, G. Magesh, D.H. Youn, J.-W. Jang, J. Kubota, K. Domen, et al. Single-crystalline, wormlike hematite photoanodes for efficient solar water splitting.

Sci. Rep. 3 (2013) 2681. doi:10.1038/srep02681.

[13] Z. Zhang, M.F. Hossain, T. Takahashi.

Self-assembled hematite $\left(\alpha-\mathrm{Fe}_{2} \mathrm{O}_{3}\right)$ nanotube arrays for photoelectrocatalytic degradation of azo dye under simulated solar light irradiation.

Appl. Catal. B Environ. 95 (2010) 423-429. doi:10.1016/j.apcatb.2010.01.022.

[14] S.R. Pendlebury, M. Barroso, A.J. Cowan, K. Sivula, J. Tang, M. Grätzel, et al. Dynamics of photogenerated holes in nanocrystalline $\alpha-\mathrm{Fe}_{2} \mathrm{O}_{3}$ electrodes for water oxidation probed by transient absorption spectroscopy. Chem. Commun. (Camb). 47 (2011) 716-8. doi:10.1039/c0cc03627g.

[15] S. Grigorescu, C.Y. Lee, K. Lee, S. Albu, I. Paramasivam, I. Demetrescu, et al. Thermal air oxidation of Fe: Rapid hematite nanowire growth and photoelectrochemical water splitting performance. Electrochem. Commun. 23 (2012) 59-62. doi:10.1016/j.elecom.2012.06.038.

[16] L. Wang, C.Y. Lee, P. Schmuki. Improved photoelectrochemical water splitting of hematite nanorods thermally grown on Fe-Ti alloys. Electrochem. Commun. 44 (2014) 49-53. doi:10.1016/j.elecom.2014.04.010. 
[17] V. a N. De Carvalho, R. a D.S. Luz, B.H. Lima, F.N. Crespilho, E.R. Leite, F.L. Souza.

Highly oriented hematite nanorods arrays for photoelectrochemical water splitting.

J. Power Sources. 205 (2012) 525-529. doi:10.1016/j.jpowsour.2012.01.093.

[18] P. Hiralal, S. Saremi-Yarahmadi, B.C. Bayer, H. Wang, S. Hofmann, K.G. Upul Wijayantha, et al.

Nanostructured hematite photoelectrochemical electrodes prepared by the low temperature thermal oxidation of iron.

Sol. Energy Mater. Sol. Cells. 95 (2011) 1819-1825.

doi:10.1016/j.solmat.2011.01.049.

[19] P.S. Shinde, A. Annamalai, J.H. Kim, S.H. Choi, J.S. Lee, J.S. Jang.

Exploiting the dynamic Sn diffusion from deformation of FTO to boost the photocurrent performance of hematite photoanodes.

Sol. Energy Mater. Sol. Cells. 141 (2015) 71-79.

doi:10.1016/j.solmat.2015.05.020.

[20] S.C. Warren, K. Voïtchovsky, H. Dotan, C.M. Leroy, M. Cornuz, F. Stellacci, et al.

Identifying champion nanostructures for solar water-splitting.

Nat. Mater. 12 (2013) 842-849. doi:10.1038/nmat3684.

[21] M.M. Momeni, Y. Ghayeb, F. Mohammadi.

Solar water splitting for hydrogen production with $\mathrm{Fe}_{2} \mathrm{O}_{3}$ nanotubes prepared by anodizing method: effect of anodizing time on performance of $\mathrm{Fe}_{2} \mathrm{O}_{3}$ nanotube arrays.

J. Mater. Sci. Mater. Electron. 26 (2014) 685-692. doi:10.1007/s10854-0142450-9.

[22] R. Morrish, M. Rahman, J.M.D. MacElroy, C. a. Wolden.

Activation of hematite nanorod arrays for photoelectrochemical water splitting.

ChemSusChem. 4 (2011) 474-479. doi:10.1002/cssc.201100066.

[23] A. Mao, N.-G. Park, G.Y. Han, J.H. Park.

Controlled growth of vertically oriented hematite/Pt composite nanorod arrays: use for photoelectrochemical water splitting.

Nanotechnology. 22 (2011) 175703. doi:10.1088/0957-4484/22/17/175703.

[24] L.M. Peter.

Energetics and kinetics of light-driven oxygen evolution at semiconductor electrodes : the example of hematite.

J. Solid State Electrochem. 17 (2013) 315-326. doi:10.1007/s10008-012-1957-3. 
[25] F. Le Formal, S.R. Pendlebury, M. Cornuz, S.D. Tilley, M. Gra, J.R. Durrant. Back Electron - Hole Recombination in Hematite Photoanodes for Water Splitting. J. Am. Chem. Soc. 136 (2014) 2564-2574.

[26] D. Maiti, V. Aravindan, S. Madhavi, P. Sujatha Devi. Electrochemical performance of hematite nanoparticles derived from spherical maghemite and elongated goethite particles. J. Power Sources. 276 (2015) 291-298. doi:http://dx.doi.org/10.1016/j.jpowsour.2014.11.097.

[27] S.K. Mohapatra, S.E. John, S. Banerjee, M. Misra. Water Photooxidation by Smooth and Ultrathin $\alpha-\mathrm{Fe}_{2} \mathrm{O}_{3}$ Nanotube Arrays. Chem. Mater. 21 (2009) 3048-3055. doi:10.1021/cm8030208.

[28] S. Shivakumara, T.R. Penki, N. Munichandraiah.

Preparation and electrochemical performance of porous hematite $\left(\alpha-\mathrm{Fe}_{2} \mathrm{O}_{3}\right)$ nanostructures as supercapacitor electrode material. J. Solid State Electrochem. 18 (2014) 1057-1066. doi:10.1007/s10008-013-23551 .

[29] A. Mao, G.Y. Han, J.H. Park. Synthesis and photoelectrochemical cell properties of vertically grown $\alpha$ $\mathrm{Fe}_{2} \mathrm{O}_{3}$ nanorod arrays on a gold nanorod substrate. J. Mater. Chem. 20 (2010) 2247. doi:10.1039/b921965j.

[30] T. Vincent, M. Gross, H. Dotan, A. Rothschild. Thermally oxidized iron oxide nanoarchitectures for hydrogen production by solar-induced water splitting. Int. J. Hydrogen Energy. 37 (2012) 8102-8109. doi:10.1016/j.ijhydene.2011.08.088.

[31] Y. Zhu, J.C. Zhang, J. Zhai, L. Jiang. Preparation of superhydrophilic $\alpha-\mathrm{Fe}_{2} \mathrm{O}_{3}$ nanofibers with tunable magnetic properties. Thin Solid Films. 510 (2006) 271-274. doi:10.1016/j.tsf.2005.09.004.

[32] S.A. Pervez, D. Kim, U. Farooq, A. Yaqub, J.H. Choi, Y.J. Lee, et al. Crystalline iron oxide nanotube arrays with high aspect ratio as binder free anode for Li-ion batteries. Phys. Status Solidi Appl. Mater. Sci. 211 (2014) 1889-1894. doi:10.1002/pssa.201330537. 
[33] C.Y. Lee, L. Wang, Y. Kado, R. Kirchgeorg, P. Schmuki.

Si-doped $\mathrm{Fe}_{2} \mathrm{O}_{3}$ nanotubular/nanoporous layers for enhanced photoelectrochemical water splitting.

Electrochem. Commun. 34 (2013) 308-311. doi:10.1016/j.elecom.2013.07.024.

[34] K. Xie, J. Li, Y. Lai, W. Lu, Z. Zhang, Y. Liu, et al.

Highly ordered iron oxide nanotube arrays as electrodes for electrochemical energy storage.

Electrochem. Commun. 13 (2011) 657-660. doi:10.1016/j.elecom.2011.03.040.

[35] K. Xie, M. Guo, H. Huang, Y. Liu.

Fabrication of iron oxide nanotube arrays by electrochemical anodization. Corros. Sci. 88 (2014) 66-75. doi:10.1016/j.corsci.2014.07.019.

[36] B. Sarma, A.L. Jurovitzki, R.S. Ray, Y.R. Smith, S.K. Mohanty, M. Misra. Electrochemical capacitance of iron oxide nanotube (Fe-NT): effect of annealing atmospheres.

Nanotechnology. 26 (2015) 265401. doi:10.1088/0957-4484/26/26/265401.

[37] A.M. Jubb, H.C. Allen.

Vibrational spectroscopic characterization of hematite, maghemite, and magnetite thin films produced by vapor deposition.

ACS Appl. Mater. Interfaces. 2 (2010) 2804-2812. doi:10.1021/am1004943.

[38] T. Sharifi, E. Gracia-Espino, H.R. Barzegar, X. Jia, F. Nitze, G. Hu, et al. Formation of nitrogen-doped graphene nanoscrolls by adsorption of magnetic $\boldsymbol{\gamma}-\mathrm{Fe}_{2} \mathrm{O}_{3}$ nanoparticles.

Nat. Commun. 4 (2013) 2319. doi:10.1038/ncomms3319.

[39] A.S. Teja, P.-Y. Koh.

Synthesis, properties, and applications of magnetic iron oxide nanoparticles. Prog. Cryst. Growth Charact. Mater. 55 (2009) 22-45.

doi:10.1016/j.pcrysgrow.2008.08.003.

[40] S. Nie, E. Starodub, M. Monti, D. a. Siegel, L. Vergara, F. El Gabaly, et al. Insight into magnetite's redox catalysis from observing surface morphology during oxidation.

J. Am. Chem. Soc. 135 (2013) 10091-10098. doi:10.1021/ja402599t.

[41] M. Lübbe, A.M. Gigler, R.W. Stark, W. Moritz.

Identification of iron oxide phases in thin films grown on $\mathrm{Al}_{2} \mathrm{O}_{3}(0001)$ by

Raman spectroscopy and X-ray diffraction.

Surf. Sci. 604 (2010) 679-685. doi:10.1016/j.susc.2010.01.015. 
[42] N.L. Wu, S.Y. Wang, C.Y. Han, D.S. Wu, L.R. Shiue.

Electrochemical capacitor of magnetite in aqueous electrolytes.

J. Power Sources. 113 (2003) 173-178. doi:10.1016/S0378-7753(02)00482-2.

[43] A. Mettenbörger, T. Singh, A.P. Singh, T.T. Järvi, M. Moseler, M. Valldor, et al. Plasma-chemical reduction of iron oxide photoanodes for efficient solar hydrogen production.

Int. J. Hydrogen Energy. 39 (2014) 4828-4835.

doi:10.1016/j.ijhydene.2014.01.080.

[44] A. Shlegel, S.F. Alvarado, P. Wachter.

Optical properties of magnetite $\left(\mathrm{Fe}_{3} \mathrm{O}_{4}\right)$.

J. Phys. C Solid State Phys. 12 (1979) 1157-1164.

[45] M. Barroso, C.A. Mesa, S.R. Pendlebury, A.J. Cowan, T. Hisatomi, K. Sivula. Dynamics of photogenerated holes in surface modified $\alpha-\mathrm{Fe}_{2} \mathrm{O}_{3}$ photoanodes for solar water splitting.

PNAS. 109 (2012) 15640-15645. doi:10.1073/pnas.1118326109.

[46] R. Gardner, D. Tanner, F. Sweerr.

Electrical properties of alpha ferric oxide. 2. Ferric oxide of high purity. J. Phys. Chem. Solids. 24 (1963) 1183-1186.

[47] S. Ahmed, J. Leduc, S. Haller.

Photoelectrochemical and impedance characteristics of specular hematite. 1. Photoelectrochemical, parallel conductance, and trap rate sudies.

J. Phys. Chem. 92 (1988) 6655-6660.

[48] X. Zhang, C. Wang, J. Chen, W. Zhu, A. Liao, Y. Li, et al.

Enhancement of the Field Emission from the $\mathrm{TiO}_{2}$ Nanotube Arrays by Reducing in a $\mathrm{NaBH}_{4}$ Solution.

ACS Appl. Mater. Interfaces. 6 (2014) 20625-20633.

[49] Q. Kang, J. Cao, Y. Zhang, L. Liu, H. Xu, J. Ye.

Reduced $\mathrm{TiO}_{2}$ nanotube arrays for photoelectrochemical water splitting. J. Mater. Chem. A. 1 (2013) 5766-5774. doi:10.1039/c3ta10689f.

[50] D.L. a de Faria, F.N. Lopes.

Heated goethite and natural hematite: Can Raman spectroscopy be used to differentiate them?

Vib. Spectrosc. 45 (2007) 117-121. doi:10.1016/j.vibspec.2007.07.003.

[51] R. Sánchez-Tovar, R.M. Fernández-Domene, D.M. García-García, J. GarcíaAntón. 
Enhancement of photoelectrochemical activity for water splitting by controlling hydrodynamic conditions on titanium anodization.

J. Power Sources. 286 (2015) 224-231. doi:10.1016/j.jpowsour.2015.03.174.

[52] N.E. Hakiki, S. Boudin, B. Rondot, M. Da Cunha Belo.

The electronic structure of passive films formed on stainless steels.

Corros. Sci. 37 (1995) 1809-1822.

[53] F. V. Herrera, P. Grez, R. Schrebler, L.A. Ballesteros, E. Muñoz, R. Córdova, et al.

Preparation and Photoelectrochemical Characterization of PorphyrinSensitized $\alpha-\mathrm{Fe}_{2} \mathrm{O}_{3}$.

Thin Films, J. Electrochem. Soc. 157 (2010) D302. doi:10.1149/1.3357257.

[54] S.S. Shinde, R.A. Bansode, C.H. Bhosale, K.Y. Rajpure.

Physical properties of hematite $\alpha-\mathrm{Fe}_{2} \mathrm{O}_{3}$ thin films: application to photoelectrochemical solar cells.

J. Semicond. 32 (2011) 013001. doi:10.1088/1674-4926/32/1/013001.

[55] I. Cesar, K. Sivula, A. Kay, R. Zboril, M. Grätzel.

Influence of Feature Size, Film Thickness, and Silicon Doping on the Performance of Nanostructured Hematite Photoanodes for Solar Water Splitting.

J. Phys. Chem. C. 113 (2009) 772-782. doi:10.1021/jp809060p.

[56] S. Shen, J. Zhou, C.-L. Dong, Y. Hu, E.N. Tseng, P. Guo, et al.

Surface Engineered Doping of Hematite Nanorod Arrays for Improved Photoelectrochemical Water Splitting.

Sci. Rep. 4 (2014) 6627. doi:10.1038/srep06627.

[57] F. Le Formal, N. Tétreault, M. Cornuz, T. Moehl, M. Grätzel, K. Sivula. Passivating surface states on water splitting hematite photoanodes with alumina overlayers.

Chem. Sci. 2 (2011) 737. doi:10.1039/c0sc00578a.

[58] X. Lu, Y. Zeng, M. Yu, T. Zhai, C. Liang, S. Xie, et al. Oxygen-deficient hematite nanorods as high-performance and novel negative electrodes for flexible asymmetric supercapacitors.

Adv. Mater. 26 (2014) 3148-3155. doi:10.1002/adma.201305851.

[59] M. Radecka, M. Rekas, A. Trenczek-Zajac, K. Zakrzewska.

Importance of the band gap energy and flat band potential for application of modified $\mathrm{TiO}_{2}$ photoanodes in water photolysis.

J. Power Sources. 181 (2008) 46-55. doi:10.1016/j.jpowsour.2007.10.082. 
[60] F. Bella, D. Pugliese, J.R. Nair, A. Sacco, S. Bianco, C. Gerbaldi, et al. A UV-crosslinked polymer electrolyte membrane for quasi-solid dyesensitized solar cells with excellent efficiency and durability.

Phys. Chem. Chem. Phys. 15 (2013) 3706-3711. doi:10.1039/c3cp00059a.

[61] F. Bella, M. Imperiyka, A. Ahmad.

Photochemically produced quasi-linear copolymers for stable and efficient electrolytes in dye-sensitized solar cells.

Journal Photochem. Photobiol. A Chem. 289 (2014) 73-80.

doi:10.1016/j.jphotochem.2014.05.018.

[62] V. Gianotti, G. Favaro, L. Bonandini, L. Palin, G. Croce, E. Boccaleri, et al. Rationalization of Dye Uptake on Titania Slides for Dye- Sensitized Solar Cells by a Combined Chemometric and Structural Approach. ChemSusChem 7 (2014) 3039-3052. doi:10.1002/cssc.201402194. 